\title{
O ouvido preparado como disparador de um ato de escuta
}

\author{
Pedro de Albuquerque Araujo ${ }^{1}$
}

\section{Resumo:}

O que move este trabalho é a noção do liame, composta a partir do encontro entre duas redes conceituais: o método de ensino musical pré-figurativo de Hans-Joachim Koellreutter e o pensamento sem imagem, de Gilles Deleuze. Eles surgem numa zona de vizinhança, dando-nos a impressão de que um é constituído pelo outro e vice-versa. No pré-figurativo, um método que coloca o pensamento em devir e no pensamento sem imagem, um movimento de desterritorialização capaz de delinear algo que ainda não existe, mas pode existir. A partir do liame eventos acontecem, se produzem, se autoproduzem.

Palavras-chave: Pré-figurativo; Pensamento sem Imagem; Devir-outro; Deleuze; Nietzsche; Koellreutter.

\section{Sobre o Liame}

A questão do liame, do latim ligamen, laço, cordão, fita; mas, então, o que se aproxima mais da na nossa intenção é ligätüra, o que significa a ação de ligar um elemento ao outro. Porém nós não estamos usando as palavras no seu sentido régio, estamos mais para o sentido nômade, da mistura, da malandragem, da miscigenação, o da periferia que está no centro e do centro que está na periferia. Da ação de um no outro, a ação de um quase desligamento que não se desliga; e com isso voltamos à idéia de ligamen, de um cordão, de uma fita muito fina, uma espécie de fio da navalha em que as forças se postam exatamente no meio, como modo de estar pulsante, vivo, e como portador de mensagens; é então, a partir dessa noção, do meio como mensageiro que podemos perceber as forças, aqui, ali, acolá, disseminadas, espalhadas, esparramadas, produzindo-se em multiplicidades maquínicas, variações maquínicas, como se fossem máquinas de tear sons, tecendo e engendrando os sons de um devir-pássaro-na-manhã,

\footnotetext{
${ }^{1}$ Mestre em Educação, Comunicação e Cultura pela UERJ/Febf
} 
que soam como máquinas de entoar cânticos, produzindo um movimento intensivo e maquinal, na relação entre-dois (que não forma par) da Natureza e Cultura, na forma informada de um círculo ceifado, aberto e em espiral (sempre!), que relativiza essa conexão, que questiona como se articulam Natureza e Cultura, no caso, como se articulam a filosofia e a música, através do dinamismo sonoro-musical, através do metasigno, através do método/conceito/afetivo, se colocando de uma maneira pré-figurativa, na acepção daquilo que é anterior à figuração (no sentido de uma circunscrição), precedendo-o enquanto momento aberto à investigação (no sentido da criação). Então podemos perceber a filosofia como uma mistura de corpos no sentido do dito e do nãodito, do escrito e do não-escrito, do saber e do não-saber; a música também segue esse caminho, do som e do que não é som (a pura intensidade), do ritmo pulsado e nãopulsado e das n combinações de timbragem, isso só para ficarmos no ambiente da música produzida por instrumentos, porque se pensarmos que música é sons ou que a música é um caminhão passando numa estrada, como já disse Cage, isso nos leva ao infinito da relação sonoro-musical ao modo de um sem fim das condições de possibilidades.

\section{O método visto como um meta-signo}

O método de ensino musical pré-figurativo tem como característica a expressão particular e específica dos termos, epistemologia e pedagogia e não trabalha com modelos prévios. Então, a partir disso nós consideramos o pré-figurativo mais que um método, sendo ele um método/conceito/afetivo, que coloca o pensamento em devir, aumentando sua potência a cada momento em que relaciona cognição e expressão e a cada instante em que os diferencia.

A epistemologia aqui é vista como um dispositivo foucaultiano, sendo o dito e o não dito de modo simultâneo, portanto, é o que está sempre inscrito como um jogo de forças heterogêneo, estando um ligado no outro. São as configurações de saber que dele nasce,

mas igualmente o condiciona. É isto que é um dispositivo: estratégias de relações de forças que sustentam saberes e por eles são sustentadas.

Já no que se refere à pedagogia como uma ação educadora são as leis imanentes à vida que regulam as forças do corpo e do espírito, colocando o conhecimento como força ativa a serviço da educação; é uma idéia ousada e criadora que só podia amadurecer no meio de um povo artista e pensador. Sendo o Homem vivo a mais alta obra de arte que 
os gregos criaram, com isso, faz com que percebam que a educação é um processo constante e em construção.

Mas foi com o sentido de potencializar as diferenças existentes no processo de aprendizagem, que Koellreutter pode criar essa metodologia de ensino. Para além da simples aplicação do complexo metodológico, o que se considera vital é a observação das diferenças que o próprio processo pré-supõe, na medida em que geram alteridades e valorizam singularidades, ambas constituintes do ato de criação.

Teremos que dizer de uma imagem do pensamento antes de nos proferirmos sobre o pensamento sem imagem. Tal imagem pode ser vista como um desenho que marca o chão, no qual só depois a filosofia se desenvolve, onde só há o possível. Porém, para Deleuze, o importante é o pensamento sem imagem, uma maneira de pensar sem um padrão pré-existente que determina de antemão o que significa pensar ou orientar-se no pensamento. Trata-se aqui de um movimento de desterritorialização capaz de delinear algo que ainda não existe, mas que pode existir. Tal pensamento pode ser relacionado a um estado de sombreamento, numa condição muito sutil entre forças que se produzem através das diferenças (de uma maneira não dialética), com a imagem do pensamento. Isso caracteriza uma zona de vizinhança, uma espécie de telhagem, ou timbragem (no sentido musical do termo), como num telhado mesmo, em que as telhas se recobrem apenas em partes, o existir no outro e pelo outro, simultaneamente, o que permite que se diga de um devir-outro. O que é um quase outro, mas não se efetiva no outro, ou como outro.

Mas o que nos interessa pesquisar é se nos domínios relativos ao sonoro (intensivo) e ao musical (extensivo), o fato de existir como outra atualização da linguagem musical, que não é a do significante nem como fala nem como palavra escrita, mas que também é afeto do corpo e afeto de um corpo afetante, pode motivar a produção estético-musical através do liame (que é ativo e criador), por algo que está entre o sonoro e o musical, que age no instante - naquele único e contingente instante - com a potência de um raio, fazendo com que o ato de escuta seja capaz de gerar-se e ser gerado.

As ressonâncias, portanto, entre o pré-figurativo e o pensamento sem imagem provocam a criação de um meta-signo, o método/conceito/afetivo, que tem por características: trabalhar sem modelos prévios, por o pensamento em devir, gerar alteridades e valorizar 
as singularidades, fazendo disso uma zona de vizinhança, trazendo a noção do deviroutro para o ato de criação e para o ato de escuta, simultaneamente.

O outro ou os signos que nos forçam a pensar à existência de um devir-outro, através do devir sonoro-musical, isto é, visto de uma maneira ampla, não é preciso produzir sons para se ter uma relação sonoro-musical. Como vemos no caso do devir Vespa-Orquídea (Mil Platôs, “Introdução: Rizoma”, p. 18), que tratado de um modo sonoro-musical não produz som algum. Porém o que nos interessa é o movimento vibratório característica intrínseca das misturas, das composições, das mesclas, que encontramos nas cores, nas temperaturas, nos sons, nos ritmos, na relação professor/aluno. É o que chamamos de timbragem. Sendo isso o que consiste na nossa acepção, o método de ensino musical pré-figurativo.

O pré-figurativo é aqui compreendido como um signo transformador e nesse caso, é visto como uma explosão de linhas múltiplas2 na relação dualista sujeito/objeto, fazendo com que esta relação dual passe a não existir mais.

O que pretendemos destacar é exatamente a diferença entre o que força o pensar e o que causa um pensamento, no sentido da produção de adestramento e seleção. Pois, vemos que, quando somos forçados a pensar por um signo externo, o que fazemos é nos expressar de maneira particular e contingente, por uma fissura silenciosa, imperceptível, por um deslocamento tátil, produzido pelas articulações entre os ritmos vitais. Criadora por excelência, tal relação não é a de causalidade, em que as respostas para os problemas postos já estão dadas de saída, mas sim, ressonâncias que engendram ecos no pensamento, não importando a solução dos problemas, mas sim, a formulação dos mesmos.

O que estamos tentando dizer são os ecos, não só no sentido das diversas ondas sonoras, mas também, das ondas de um pensamento sem imagem que são expressas e impressas do/no pensamento. Como uma caixa de ressonância, ou caixa acústica, de um Contrabaixo ou Violoncelo, na qual as ondas sonoras produzidas pela vibração das cordas provocam uma espécie de sulco, de cava, muito sutil, na parte interna da madeira em que tais caixas são construídas. E o traço sutil das ondas sonoras de um pensamento sem imagem, de tanto ser sulcado, produzem o modo de expressão, em que cada

\footnotetext{
${ }^{2}$ A construção de linhas múltiplas quer dizer exatamente um rizoma.
} 
instrumento, em cada caixa acústica, se torna diferenciado. Assim como cada maneira de pensar, do modo como concebemos, é particular e contingente. Citando Deleuze:

Não podemos nos servir da causalidade, uma vez que se trata de uma relação dos efeitos entre si. (...) o que faz com que uma vida (...) apesar de toda a variedade daquilo que lhe ocorre, seja atravessada por uma só e mesma fissura, que toque uma só e mesma melodia em todos os tons possíveis com todas as palavras possíveis, não são relações de causa e efeito, mas um conjunto de correspondências nãocausais, formando um sistema de ecos, de retomadas e de ressonâncias, um sistema de signo (Deleuze, 1974, p. 176 grifos meus).

Portanto o meta-signo pré-figurativo é visto como um signo que força o pensar, pois, ele se coloca para além das proposições lingüísticas e da linguagem musical ordinária. A força que força o pensar é contingente e criativa, exigindo um trabalho com velocidades e lentidões, que já não são suas e exatamente por isso geram deslocamentos e produzem linhas de fuga, a partir de uma escuta inconsciente, cujo significado e significante não podem alcançar, por se postarem no plano da consciência.

A noção de escuta inconsciente não está nem no sujeito nem no objeto, está no signo, no meta-signo sendo que este se auto-produz, no sentido de afetar e ser afetado, da mesma maneira que uma experiência estética em que o modo afetar não se dá na consciência, mas em outro modo de inconsciência que não é físico nem mental, porém ao mesmo tempo é físico e mental3.

Do mesmo modo que no conto de Franz Kafka, A grande muralha da China, em que os nômades se instalam na praça central de Pequim e fazem do Imperador um prisioneiro em seu próprio palácio (como em 1989, os estudantes que tomaram a Praça da Paz Celestial). Assim o modo nômade de agir é como o meta-signo pré-figurativo, porque produz e traz à crítica e à criação de uma maneira sonoro-musical, para a música, às artes, à filosofia, às línguas, à política, etc.

O nômade (à qualidade nômade) age por variações das leis, dos costumes, dos desejos, imprimindo à capital, ao centro, suas estranhezas, suas esquisitices. Suas bocas são tão

\footnotetext{
${ }^{3}$ Não estamos falando aqui da dicotomia Consciente versus Inconsciente, no sentido freudiano.
} 
escancaradas e seus dentes tão afiados que falam como gralhas e numa língua quase incompreensível (os nômades agem rizomaticamente).

Talvez por isso o pré-figurativo seja tão semelhante à qualidade nômade. Pois o metasigno está sempre dentro e fora, da cultura, da linguagem, do território em que ocupa. Não entra em confronto direto com o que recusa não aceita a dialética como forma de oposição, mas ao contrário se afirma na diferença. Quanto mais submetido ao campo adversário, mais deslizante, mais escorregadio, mais questiona o jogo ou subverte-lhe o sentido, desterritorializa-o. O nômade (no sentido da qualidade), assim como o metasigno pré-figurativo, é um desterritorializador por excelência, uma potência desterritorializante, aquele que faz da desterritorialização o seu território.

Então por que é um equívoco, para nós, questionar o pré-figurativo perguntando pelo o que ele é? Porque o que nos interessa pesquisar está na metamorfose da relação professor/aluno, que o meta-signo método/conceito/afetivo proporciona, assim sendo, a maneira pela qual podemos atingir esta questão é perguntando como ele opera?

Em consequencia tal fato se dá através do liame musical, dos signos que nos forçam a pensar. Tais signos são os signos que proporcionam um movimento, uma velocidade: os acordes dissonantes, os compassos ímpares, as polirritmias, os politonalismos, os microtonalismos, além de outros materiais que também não fogem ao sistema maior/menor da música tonal.

Apesar dos exemplos dados ainda se colocarem dentro dos limites do tonalismo, eles podem ser a maneira mais gutural (no sentido de que é através destes signos que forçamos o pensamento) de se aproximar da região onde essa fronteira exista como um liame sonoro-musical.

O que entendemos por fronteira se concebe por um "sistema aberto", em que, são os resultados dos dinamismos variáveis, tanto no interior como no exterior dos sistemas. As fronteiras dos sistemas abertos, de que os organismos vivos são um bom exemplo, derivam do caráter convencional descritivo, não correspondendo, assim, as descontinuidades dos sistemas filosófico-científicos. "Neste sentido, as sociedades humanas reais são sistemas abertos sem fronteiras” (Leach, 1985, p. 16).

Percebemos que, durante uma aula de música, o simples fato de se executar um compasso ímpar ou um acorde dissonante já seja capaz de produzir uma passagem, um caminho, e é exatamente no caminhar percorrido pelo caminhante que, definiremos o 
momento/movimento/velocidade como ato de criação. $\mathrm{O}$ ato criativo é um pensamento que é incitado por um signo externo que chega ao máximo de excitação à maneira de um turbilhão. Citando o “Tratado de Nomadologia: a máquina de guerra” (Deleuze \& Guattari, 1997):

É preciso aqui, fazer a distinção entre velocidade e movimento: o movimento pode ser muito rápido, nem por isso é velocidade; a velocidade pode ser muito lenta, ou mesmo imóvel, ela é, contudo, velocidade. O movimento é extensivo, a velocidade, intensiva. $O$ movimento designa o caráter relativo de um corpo considerado como "uno", e que vai de um ponto a outro; a velocidade, ao contrário, constitui o caráter absoluto de um corpo cujas partes irredutíveis (átomos) ocupam ou preenchem um espaço liso (Deleuze \& Guattari, 1997, p. 52) $)^{4}$.

Segundo Deleuze (1974), em Lucrécio há uma gradação que nos faz passar do tempo pensável ao tempo sensível e vice-versa, o tempo pensável (racional) se torna menor que o mínimo de tempo sensível (afetivo). Pois é nesse tempo da sensibilidade (no sentido de lugar afetivo) onde se está totalmente invadido, tomado por uma velocidade desmedida, e numa somatória qualitativa e quantitativa de simulacros idênticos. Ai, nesse ponto, é que há a mistura do tempo no espaço, em que o onde se entranha no quando, e é como ocorre o ato de criação.

A música, então, como fenômeno sonoro-musical (ato de criação e ato de escuta), numa concepção pré-figurativa, é vista como pura potência, onde se afirma como crítica e no mesmo sentido, criadora. A crítica criativa, portanto, expressa a ação de um modo ativo. Não é a vingança, é uma investida, é uma visada, é uma estocada positiva da vida. É também a eterna destruição e re-construção simultâneas, em que podemos compreender a crítica criativa, como uma dinâmica violenta, numa velocidade de diferença e repetição, sempre voltando e sempre devindo produtivamente.

\section{Referências Bibliográficas:}

\footnotetext{
${ }^{4}$ Podemos fazer aqui uma ligação direta entre o modo sonoro e a velocidade.
} 
DELEUZE, Gilles. Lógica do Sentido. Tradução de Luiz Roberto Salinas Fortes. São Paulo: Perspectiva, 1974.

DELEUZE, Gilles; GUATTARI, Felix. Mil Platôs: Capitalismo e Esquizofrenia. Vol. 1. Tradução de Aurélio Guerra Neto e Célia Pinto Costa. “Introdução: Rizoma”, pp. 1137, 1995. Vol. 5 Tradução de Peter Pál Pelbart. Rio de Janeiro: Ed. 34. "Tratado de Nomadologia: a máquina de guerra”, pp. 11-110, 1997.

LEACH, Edmund. Anthropos in Enaudi - Enciclopédia. Tradução de Rui Pereira e Teresa Bento. Edição Portuguesa, Imprensa Nacional - Casa da Moeda, 1985. 